\begin{tabular}{|c|c|c|c|}
\hline Article Info & RESEARCH ARTICLE & ARAŞTIRMA MAKALESİ & \\
\hline Title of Article & \multicolumn{2}{|c|}{$\begin{array}{c}\text { The Black Sea Economic Cooperation } \\
\text { (BSEC) Organization: Civil Cooperation } \\
\text { Strategies }\end{array}$} & \\
\hline $\begin{array}{l}\text { Corresponding } \\
\text { Author }\end{array}$ & \multicolumn{2}{|c|}{$\begin{array}{l}\text { Prof. Dr. Yüksel Demirkaya } \\
\text { Marmara Üniversity, Faculty of Political Sciences, Dept. of PublicAdministration, } \\
\text { ydemirkaya@marmara.edu.tr }\end{array}$} & \\
\hline $\begin{array}{l}\text { Received Date } \\
\text { Accepted Date }\end{array}$ & \multicolumn{2}{|l|}{$\begin{array}{l}24.10 .2020 \\
31.12 .2020\end{array}$} & \\
\hline Author / Authors & Yüksel Demirkaya & ORCID: 0000-0002-2683-8579 & \\
\hline How to Cite & \multicolumn{2}{|c|}{$\begin{array}{l}\text { Demirkaya, Y., (2020). The Black Sea Economic Cooperation (BSEC) Organization: } \\
\text { Civil Cooperation Strategies, Kent Akademisi, Volume, 13, Issue 4, Pages, 751-760 }\end{array}$} & $\begin{array}{l}\text { Kent Akademisi } \\
\text { Urban Academy }\end{array}$ \\
\hline
\end{tabular}

\title{
Karadeniz Ekonomik İşbirliği Teşkilatı: Sivil İşbirliği Stratejileri
}

Prof. Dr. Yüksel Demirkaya ${ }^{1}$

\section{ABSTRACT:}

Efforts by individual countries or groups of Black Sea's surroundings countries to cooperate have remained on the agenda of these countries for the last quarter of a century. However, it was a generally accepted assessment that the point reached in spite of all the struggles was not satisfactory. Especially today, we are targeting very serious regional war scenarios, which has found supporters on global and regional scale, which threaten peace and tranquility. It has become more important than ever that the countries of the region come together and join forces. On the other hand, in view of the neo-liberal global economic movements, it is understood that the countries of the region are in need of each other. These countries need to come together and establish a dialoge and partnership networks.From this point of view, efforts to develop socioeconomic and cultural relations between the countries of the Black Sea region at the institutional level (public and private sector) in such a way that the people are directly involved are strategically important for the socio-cultural integration of societies and the development of commercial relations as well as to ensure regional security. In our article, after analyzing the structure and activities of the Black Sea Economic Cooperation Organization, which will celebrate its 30th anniversary in 2023, what the strategic relationship formats between the countries in the region can be and how they can be developed will be discussed.

\footnotetext{
${ }^{1}$ Marmara Üniversitesi, Siyasal Bilgiler Fakültesi, Yönetim Bilimleri Ana Bilim Dalı, Yönetişim ve Sivil Toplum Kuruluşları Bilim Dalı ydemirkaya@marmara.edu.tr
} 
KEYWORDS: Black Sea Economic Cooperation, Governance, NGO, CSO, Civil Cooperation Strategies

ÖZ:

Karadeniz Ekonomik İşbirliği Teşkilatını (KEİ) farklı bir bakış açısıyla incelemek istediğimiz bu yazımızda, bölge ülkelerinin karşılıklı siyasi mücadelerine değinmeyecek ve organizasyonun işleyişinde etkili olan siyasal tartışmaların, bölge ülkeleri arasındaki gruplaşmalarının veya ikili ciddi sorunları olan ülkelerin özel durumlarını yazımızda kapsam dışı bırakacağız. Zira bu yazı ile KEİ'nin kuruluş amaçları doğrultusunda işleyişini analiz ederek farklı bir bakış açısıyla yeni eylem stratejilerinin neler olabileceği konusunda fikir yürüteceğiz. Bu yazıyı kaleme almamızda temel esin kaynağımız, KEİnin bazılarına göre alternatif olarak kurulduğu, bazılarına göre ise işleyiş ve hedefleri bakımından örnek alındığı Avrupa Birliğinin (AB) ekonomik bir birlikten siyasal bir birliğe doğru yapılanmasından etkin olan hükümet dışı organizasyonların (NGOs) ve sivil toplum kuruluşlarının (CSOs) başarılarıdır. Yani yazımızın hemen başında iddiamız odur ki, bölge güvenliği ve küresel güç dengesi açısından çok büyük bir öneme sahip olan, KEİnin kendisinden beklenileni sergileyebilmesi için hedefleri doğrultusunda sivil toplum kuruluşlarıyla birlikte strateji üretmeli ve uygulamalıdır. Bu noktadan hareketle, Karadeniz bölge ülkeleri arasındaki sosyo-ekonomik ve kültürel ilişkilerin kurumsal düzeyde (kamu ve özel sektör) halkın doğrudan içinde olacağı şekilde geliştirilmesi yönündeki uğraşlar toplumların kaynaşması ve ticari ilişkilerin gelişmesinin yanında bölgesel güvenliğin sağlanması için stratejik önem taşımaktadır. Bu kapsamda yazımızda 2023 yılında kuruluşunun 30. yılını kutlayacağımız Karadeniz Ekonomik İşbirliği Teşkilatının yapısını ve faaliyetini analiz ettikten sonra, bölge ülkeleri arasında sivil stratejik ilişki formatlarının neler olabileceği ve nasıl geliştirilebileceği üzerinde durulacaktır.

ANAHTAR KELIMELER: Karadeniz Ekonomik İşbirliği, Yönetişim, STK, Sivil İşbirliği Stratejileri 


\section{Karadeniz Ekonomik İşbirliği Teşkilatı: Sivil İşbirliği Stratejileri}

\section{GíRiş}

Karadeniz Ekonomik İşbirliği Teşkilatını (KEİ) farklı bir bakış açısıyla incelemek istediğimiz bu yazımızda, bölge ülkelerinin karşlıklı siyasi mücadelerine değinmeyecek ve organizasyonun işleyişinde etkili olan siyasal tartı̧̧maların, bölge ülkeleri arasındaki gruplaşmalarının veya ikili ciddi sorunları olan ülkelerin özel durumlarını yazımızda kapsam dışı bırakacağız. Zira bu yazı ile KEİ'nin kuruluş amaçları doğrultusunda işleyişi analiz ederek farklı bir bakış açısıyla yeni eylem stratejilerinin neler olabileceği konusunda fikir yürüteceğiz. Bu yazıyı kaleme almamızda temel esin kaynağımız, KEI'nin bazılarına göre alternatif olarak kurulduğu, bazılarına göre ise işleyiş ve hedefleri bakımından örnek alındığı Avrupa Birliğinin (AB) ekonomik bir birlikten siyasal bir birliğe doğru yapılanmasından etkin olan hükümet dışı organizasyonların (NGOs) ve sivil toplum kuruluşlarının (CSOs) başarılarıdır. Yani yazımızın hemen başında iddiamız odur ki bölge güvenliği ve küresel güç dengesi açısından çok büyük bir öneme sahip olan potansiyeli olan KEİ kendisinden beklenileni sergileyebilmek için hedefleri doğrultusunda sivil toplum kuruluşlarıyla birlikte strateji üretmeli ve uygulamalidır.

Nitekim Karadeniz etki sahasındaki ülkelerin karşılıklı bireysel veya gruplar halinde işbirliğini geliştirme çabaları son çeyrek yüzyılda ilgili ülkelerin sürekli gündemlerinde kalmıştır. Ancak günümüze kadar tüm çabalara rağmen gelinen noktanın iç açıcı olmadığı genel kabul gören bir değerlendirmedir (Yalçınkaya, 2017). Özellikle günümüzde barışı ve huzurumuzu tehdit eden küresel ve bölgesel ölçekte taraftar bulmuş çok ciddi savaş senaryoları bölgemizi hedef almaktadır. Örneğin Rusya ile Ukrayna, Rusya ile Gürcistan, Azerbaycan ile Ermenistan, Türkiye ile Ermenistan, Türkiye ile Yunanistan arasında savaş çıkartabilecek nitelikte çözüm bekleyen sorunlar bulunmaktadır. Dolayısıyla bölge ülkelerinin bir araya gelerek güç birliği yapmaları her zamankinden daha önemli hale gelmiş bulunmaktadır. Öte yandan neo-liberal küresel ekonomik hamleler karşısında, bölge ülkelerinin birbirine muhtaç olduklarını ziyadesiyle anlaşılmıştır (Demirkaya, 2006). Örneğin 2015 yılında Rusya Federasyonu ve Türkiye Cumhuriyeti arasında yaşanan 'uçak düşürme krizi' ile başlayan ve akabinde yaşananlar yukarıda ifade edilen tezi doğrular nitelikte önemli bir örnek olaydır. ${ }^{2}$

Burada asıl üzerinde durmak istediğimiz konu; Rusya ile Türkiye'nin çok tehlikeli bir sıcak çatışmanın eşiğinden dönmeleri, karş̧1ıklı ağır politik söylemlere ve ekonomik yaptırımlara rağmen kısa zaman içinde karşıllklı diyaloğu kurabilmişler ve tekrar işbirliğini tesis edebilmişlerdir. $\mathrm{Bu}$ başarının arkasında iki ülke halkının tüm yaşananlara rağmen birbirlerine güvenmeleri ve sorunu rahatlıkla çözebileceklerine dair olan inançları yatmaktaydı. Halkların birbirlerine olan söz konusu güven ve sempatileri politikacıları çözüm yolunda cesaretlendirmiştir. Bu karşıllklı güven ve inancın temelinde ise son yıllarda geliştirilen sosyo-ekonomik ve kültürel ilişkilerin sağlamlığı yatmaktadır. Nitekim Rus uçağının düşürülmesinde sonra her iki ülkenin de basın yayın

\footnotetext{
2 Rus Hava Kuvvetleri'ne ait Suhoy Su-24 tipi savaş uçağı sınır ihlali gerçekleştirdiği iddiasından dolayı Türk Hava Kuvvetleri tarafından 24 Kasım 2015 tarihinde füzeyle vurularak düşürülmüşsür. Olayın ciddiyeti, soğuk savaşsüreci ve sonrasında ilk kez bir NATO üyesi tarafından düşman unsur sayılarak bir Rus uçağının düşürülmesidir. Yani beklenmedik bir zamanda ve yerde gerçekleşen bu olay 3. Dünya savaşını başlatabilecek bir krizin ateşlenmesi olarak değerlendirilebilirdi.
} 
organlarında itidal çağrıları ağır basmış ve çeşitli meslek kuruluşları ve sivil toplum örgütleri, diyaloğun esas alınması yönünde gayretler göstermiştir. Her iki ülkenin siyasetçileri ve kurumlarının çabalarının ötesinde bir çaba gösteren sivil toplum kuruluşları krizin atlatılmasında çok büyük bir rol almışlardır. İkinci dünya savaşından sonra yaşanan en tehlikeli askeri krizlerden birisinin kazasız-belasız atlatılmasında etkin rol alan söz konusu bu sivil inisiyatif hem Türkiye ve Rusya'nın ve hemde tüm bölge ülkelerinin gelecekteki ilişkilerin şekillenmesinde etkin aktörlerin kimler olması gerektiği konusunda önemli ipuçları vermiştir.

Bu noktadan hareketle, Karadeniz bölge ülkeleri arasındaki sosyo-ekonomik ve kültürel ilişkilerin kurumsal düzeyde (kamu ve özel sektör) halkın doğrudan içinde olacağı şekilde geliştirilmesi yönündeki uğraşlar toplumların kaynaşması ve ticari ilişkilerin gelişmesinin yanında bölgesel güvenliğin sağlanması için stratejik önem taşımaktadır.

Bu kapsamda yazımızda 2023 yılında kuruluşunun 30. yılını kutlayacağımız Karadeniz Ekonomik İşbirliği Teşkilatının yapısını ve faaliyetini analiz ettikten sonra, bölge ülkeleri arasında sivil stratejik ilişki formatlarının neler olabileceği ve nasıl geliştirilebileceği üzerinde durulacaktır.

\section{Karadeniz Ekonomik İşbirliği (KEI) Teşkilatı}

1.1. Kuruluş Amacı: KEİ, üyesi ülkelerin sosyo-ekonomik potansiyellerinden, coğrafi avantajlarının, ekonomilerinin birbirlerini tamamlayıcı özelliklerinden yararlanarak aralarındaki ikili ve çok taraflı ekonomik, teknolojik ve sosyal ilişkilerini çeşitlendirmeleri ve geliştirmeleri hedeflenmiştir. Böylelikle bölge ülkeleri arasındaki potansiyel ve muhtemel sorunların çözümü çaba göstermek ve Karadeniz havzasının bir barış, istikrar ve refah bölgesi olmasını amaçlamaktadır. $\mathrm{Bu}$ amaca ulaşmak için seçilen araç ise öncelikle ekonomik işbirliğidir. $\mathrm{Bu}$ yönüyle AB'nin taklit edildiği söylenebilir. Nitekim bölgede ekonomik işbirliğini tesis etme amacı güden KEİ'nin temel özelliklerinden birisi, işbirliğine ve dış dünyaya açık yapılanmasıdır. Zira Karadeniz havzasında olduğu değerlendirilmeyen olan birçok ülkenin çeşitli formatlarda KEI'ye katılımına sıcak bakılmıştır. Avusturya, Hırvatistan, Çek Cumhuriyeti, Mısır, Fransa, Almanya, Belarus, İsrail, İtalya, Polonya, Slovakya, Tunus, ABD, AB Komisyonu, Karadeniz Komisyonu, Uluslararası Karadeniz Kulübü ve Enerji Şartı Sekretaryası, KEİ toplantılarına gözlemci olarak katılmaktadırlar. Macaristan, İngiltere, İran, Karadağ, Ürdün, Japonya, Kore ve Slovenya ise Sektörel Diyalog Ortağı Statüsünde toplantılara iştirak etmektedirler (www.mfa.gov.tr). ${ }^{3}$

Örgütte, Genel Sekreter Birinci Yardımcılığı görevi daimi olarak Türkiye’ye tahsis edilmiştir. KEİ'nin karar organı olan Dışişleri Bakanları Konseyi yılda iki kez toplanarak uzlaşma (oydaşma: çoğunluğun aynı düşüncede birleşmesi) yoluyla kararlar almaktadır. Üye ülkelerin Dışişleri Bakanlarını temsil eden ve onlar adına hareket eden Yüksek Düzeyli Memurlar Komitesinin ise temel görevi, Bakanlar Konseyinin aldığı karar ve tavsiyelerin takip edilmesi ve uygulanmasını sağlayarak, gerektiğinde Bakanlar Konseyine tavsiyelerde bulunmaktır. KEI'nin kurucu üyeleri Türkiye, Azerbaycan, Ermenistan, Gürcistan, Moldova, Rusya Federasyonu, Ukrayna, Bulgaristan ve Romanya; Sonradan Katılan Üyeler ise Arnavutluk, Sirbistan ve Yunanistan olarak gözükmektedir (www.mfa.gov.tr).

\footnotetext{
${ }^{3}$ http://www.mfa.gov.tr/karadeniz-ekonomik-isbirligi-orgutu-_kei_tr.mfa
} 


\subsection{Karadeniz Ekonomik İşbirliği Teşkilatı Organları}

\subsubsection{Zirve:}

KEİye üye ülkelerin Devlet ya da Hükümet Başkanlarının katılımıyla yılda bir kez dönem başkanlığını üstlenmiş olan üye ülkenin ev sahipliğinde toplanmaktadır. Genelde birlik ve beraberlik vurgusunun yapıldığı ve alt organlarca alınan kararların tebliğ edilerek kamuoyuna duyurulduğu toplantılar olarak bilinmektedir.

\subsubsection{Dışişleri Bakanları Konseyi (DBK)}

KEI'nin karar alma organı olarak altı ayda bir toplanmaktadır. KEI'nin yol haritasının belirlenmesi, temel stratejilerin oluşturulması ve genel olarak işleyişinden sorumlu organ olarak, alt birimlerin kurulması, eylem planlarının belirlenmesi ve kararların değerlendirilmesinden, diğer ülkelerin gözlemci statüsü taleplerinin tanınması ile ilgili kararların alınmasından, iç tüzüğün oluşturulması, kabul ve değiştirilmesi gibi konulardan sorumludur. Konseyin başkanı, dönem başkanlığını üstlenmiş olan ülkenin Dışişleri Bakanıdır. Dönem başkanlığı, ülke isimlerinin İngilizce alfabetik yazılma sırasına göre, altı ayda bir değişir. Konsey öncesinde gerekli hazırlıkları yapmak ve gündemi hazırlamak üzere Yüksek Düzeyli Memurlar çalıştayları yapılmaktadır. Bu çalıştaylarda direkt konseye bağlı olarak oluşturulmuş olan komisyonların raporları öncelikle dikkate alınmaktadır. Nitekim bu amaçla Dışişleri Bakanlar Konseyine bağlı aşağıdaki gibi çalışma grupları oluşturulmuştur:

- İstatistik Veri Değişimi

- Banka ve Finans İşbirliği

- Ticari ve Sınayi İşbirliği

- Tarım ve Tarımsal Sanayi İşbirliği

- Ulaşım ve İletişim İşbirliği

- Çevrenin Korunması İşbirliği

- Bilim ve Teknoloji İşbirliği

- Suç ve Suçlularla Mücadele İşbirliği

Ayrıca ihtiyaca göre benzeri çalışma grupları oluşturulabileceği kararlaştırılmıştır.

\subsubsection{Karadeniz Ekonomik İşbirliği Parlamenterler Asamblesi (KEİPA)}

26 Şubat 1993 tarihinde Bulgaristan ve Yunanistan haricindeki teşkilat üyesi ülkelerin katılımıyla kurulmuştur. 1995 yılında Yunanistan, 1997 yılında Bulgaristan da üye olmuşlardır. Parlamenterler Asamblesinin kuruluş amacı, KEİ bünyesinde çeşitli platformlarda alınan kararların uygulanabilmesi için gerekli yasal düzenlemelerin yapılmasını temin etmek, KEİnin amaçları konusunda bilinç ve farkındalık oluşturmak amacıyla üye ülkelerin kamuoyuna tanıtım faaliyetleri organize etmek, KEİ üye ülkeleri arasında ülke demokrasilerinin gelişmesine katkıda bulunacak eylemler planlamak, diğer uluslararası kuruluşlarla KEİ üyeleri arasındaki işbirliğini geliştirecek stratejiler geliştirmek şeklinde özetlenebilir. Sekretarya hizmetlerini İstanbul merkezli olan KEIPA Uluslararası Sekretaryası yürütmektedir.

\subsubsection{Karadeniz Ekonomik İşbirliği İş Konseyi (KEİK)}

31 Ağustos 1993 tarihinde KEİ üye devletlerinin özel sektörlerini temsil edebilecek bir mekanizmanın oluşturulması kararlaştırılmıştır. Bu organizasyonun KEİ ülkelerin ticari ve sınai 
işbirliğini geliştirme amacına yönelik olarak çalışması planlanmıştır. Yönetim kurulunda her ülkeyi temsilen bir üye bulunmakta, konusuna göre çalışma grupları oluşturabilmekte ve daimi Sekretaryası İstanbul'da bulunmaktadır.

\subsubsection{KEİ Uluslararası Sekretaryası}

10 Aralık 1992 tarihinde İstanbul merkezli olarak kurulmuştur. Başlıca görevleri arasında Yüksek Düzeyli Memurlar toplantıları doğrultusunda DBK için gündeminin hazırlanması, toplantılara katılımcı devletler tarafından sunulan belgelerin tanzimi, KEİ toplantılarına idari-teknik desteğin sağlanması ve KEİ belgelerinin tanzim edilmesi ve arşiv çalışmalarının oluşturulması gibi konular bulunmaktadir.

\subsubsection{KEI Ticaret ve Kalkınma Bankası (KTKB)}

Üye ülkeler arasında ticari ve sınai işbirliğini geliştirecek projelere finansman sağlamak üzere kurulan KTKB, faaliyetlerine 1999 yılında merkezi olan Selanik’te başlamıştır. Üye ülkelerin ekonomik büyüklüklerine göre bankanın sermayesine katkıda bulunmaları sağlanmıştır.

\subsubsection{KEİ İstatistik Veri ve Ekonomik Bilgi Değişimi Eşgüdüm Merkezi}

KEİ Uluslararası Sekretaryasının çalışmaları doğrultusunda veri toplanması ve analizi konusunda daha ileri bir adım olarak atılmıştır. KEİ Dışişleri Bakanları'nın 10 Aralık 1992 tarihinde Antalya'da yapılan ilk toplantısında onaylanan bir kararla kurulmuştur. Türkiye İstatistik Kurumu aynı zamanda "KEİ İstatistik ve Ekonomik Bilgi Değişimi Koordinasyon Merkezi” olarak görev yapmaktadır. Lojistik ve mali desteği TÜİK tarafından karşılanmaktadır. Merkezin programı, üye ülkeler arasında istatistik veri toplama, istatistik veriler için ortak data bank oluşturma, verilerin uyumlaştırılması için toplantılar ve eğitim programları düzenleme gibi faaliyetleri içermektedir. "Türkiye'nin KEİ Ülkeleri ile Yaptığı Dış Ticareti” ve "KEİ ülkelerinin Sosyal ve Ekonomik Göstergeleri” adlı iki ayrı süreli periyodik yayın çıkarmaktadır.

\subsubsection{Uluslararası Karadeniz Etütleri Merkezi}

Karadeniz Ekonomik İşbirliği Örgütü'nün hedeflerini geliştirmek, yeni imkanları ve işbirliği alanlarını analiz etmek üzere Uluslararası Karadeniz Etütleri Merkezi Atina merkezli olarak kurulmuştur. Merkez aynı zamanda bir araştırma kuruluşu olarak da görev yapmaktadır. Merkez, bir süre önce KEİ Daimi Sekretaryası ile işbirliği halinde "Gelecek İçin Ekonomik Gündem" başlıklı bir rapor hazırlanmıştır. Rapor KEİ'nin karar organı olan Dışişleri Bakanları Konseyince kabul edilmiştir (KEİ'nin organları ve işleyişleri ile ilgili bölüm bilgileri Kalkınma Bakanlığı web sitesinde derlenerek analiz edilmiştir. www3.kalkinma.gov.tr)4.

\section{KEI'nin Faliyetleri:}

Üye ülkeler arasında bölgeler arasında ticaretin geliştirilmesi KEI'nin temel kuruluş amaçlarındandır. Bu doğrultuda ticari ve sınai işbirliklerin geliştirilmesi, ortak AR-GE çalışmaları ve teknoloji transferlerinin önünün açılması hedeflenmiştir (Kiraz, 2018). Öncelikle sınır ve kıyı ticareti, malların ve kişilerin hareketlerinin kolaylaştırılması amacıyla gerekli kolaylıkların sağlanması yönünde çalışmaların yapılması amaçlanmıştır.

\footnotetext{
4 Karadeniz Ekonomik İşbirliği Teşkilatı Organları bölümü aşă̆ıdaki linkten derlenmiştir. http://www3.kalkinma.gov.tr/PortalDesign/PortalControls/WebContentGosterim.aspx?Enc=51C9D1B02086EAFBF69CEF5F299AE5B4
} 
Üye ülkeler ve işbirliği yapılanlar arasında iletişim altyapısının oluşturulması öncelikli hedefler arasında sayılmıştır. Zira iletişim ve ulaştırma altyapılarının entegre edilmesi KEİ için Stratejik bir zorunluluk olarak gözükmektedir. Özellikle KEİ bölgesindeki petrol ve doğalgaz kaynaklarının çevreye zarar vermeden pazarlara ulaştırılması hem bölge ülkeleri hem de dünya için hayati derecede önem arz etmektedir. Nitekim dünya petrol ve doğalgaz rezervlerin önemli bir bölümü KEİ bölgesinde bulunmaktadır. Halihazırda KEİ bölgesi Avrupa ve Asya arasında önemli bir enerji köprüsü olarak değerlendirilmektedir. Bu yönüyle özellikle Avrupa Birliğinin merceği altındadır. Tsardanidis'e göre (2005) Avrupa'nın ve Asya'nın güvenliği için AB ve KEİ arasında özellikle ulaşım, enerji ve telekomünikasyon alanında altyapı projelerinde işbirliği yapılmalıdır. Çevrenin korunması ve nükleer güvenliği sağlanması da bu iki bölgesel organizasyonun sorumluluğunda olmalidır.

KEI'nin eylem sistematiği Dışişleri Bakanlar Konseyinin faaliyetleri incelenerek anlaşılabilir. Konseyin kararıyla kurulan ticaret ve ekonomi, ulaştırma, enerji, haberleşme, bilim ve teknoloji gibi konular başta olmak üzere çeşitli alanlarda çalışma grupları yardımcı alt çalışma komisyonları olarak faaliyet göstermektedir. Herhangi bir iş girişimi, proje tasarımı veya işbirliği fikri konularına göre öncelikle bu çalışma komisyonlarında tartışılmaktadır. Komisyonlarda şekillenen öneriler gündem önerisi olarak Bakanlar Konseyine raporla halinde sunulmaktadır.

Görüldüğü gibi KEİ Avrupa Birliğinde olduğu gibi çok değişik alanlarda benzer örgütler kurmuş ve faaliyetler için çalışma araç ve stratejileri oluşturmuştur. Bu minval üzere 27 yıldır faaliyette olan KEİ'nin ismini çok daha iyi duyurabilmesi ve çok daha başarılı çalışmalarıyla bölgenin güvenliğine ve ekonomik refahına katkıda bulunabilmesi gerekiyordu. Çünkü benzer şekilde kurulan Avrupa Birliği henüz 10. Yılında rüş̧ünü ispat etmiş ve Avrupa ülkelerinin ısrarla içinde bulunmak istediği vazgeçilmez bir sosyo-ekonomik işbirliği örgütü olarak bölge ülkeleri arasında sıkı bir işbirliği platform olmuştu.

KEİ'nin öngörülenin aksine henüz başarılı olarak değerlendirilmemesinin değişik siyasi sebepleri vardır. Ancak yazımızın başında belirtiğimiz gibi, KEİ faaliyetlerini ve performansını politik perspektiften değerlendirmeyeceğiz. Ticari alandaki başarısızlı̆̆ın ise önemli sebepleri arasında, KEİ'nin üye ülkeleri arasında katma değeri ve teknoloji donanımı yüksek arge bazlı ürünlerin ihracatında karşılaştırmalı üstünlük bakımından oldukça zayıf durumda olması gösterilmektedir. Erkan ve Batbaylı'ya göre (2017) bu durum KEİ üye ülkelerinin ihracatındaki katma değerin düşük, ithalatındaki katma değerin ise büyük olduğunu gösteriyor. Bölge ülkelerinin ihracatındaki karşılaştırmalı üstünlüklerin daha çok katma değeri düşük ürünlere dayanması, bilimsel ve teknolojik ürünlerde sözü edilen ülkeleri dışa bağımlı hale geldiği anlaşılmaktadır. Nihayetinde, karşılaştırmalı üstünlükleri daha çok hammadde ve emek yoğun malların ihracatına dayanan bölge ülkelerin dış açık vermesi kaçınılmaz olacaktır (Erkan ve Batbaylı, 2017).

Görüldüğü gibi spesifik değerlendirmeler ile spesifik alanlarda başarı ve başarısızlık alanları tespit edilebilir. Ancak büyük resme odaklanarak, karşılıklı güvenin oluşturulması amacıyla iletiş̧im ve diyalog kapılarının açık tutulması bakımından KEİ'nin performansının sorgulanmasının daha öncelikli olduğu söylenebilir. Nitekim bölge ülkeleri arasında karşılıklı güvenin tesis edilmesiyle sosyo-ekonomik ilişki yolları açılabilir. Dolayısıyla karşılıklı menfaatlerin gözetilerek bölge refahının artırılması öncelikli amacıyla kurulan KEİ'nin hedefleri doğrultusunda yeni bir stratejik eylem planı hazırlaması bir zorunluluk olarak gözükmektedir. 


\section{SONUÇ YERINE: YENI İ̧̧BIRLIIĞi STRATEJILERİ:}

Ulusal, bölgesel veya küresel ölçekte barış ve refah için stratejiler üretmesi gereken uluslararası örgütlerin önemi günümüzde tartışılmaz durumdadır. Bu kapsamda hem devletlerin kendi içinde, hem de üyesi oldukları uluslararası örgütlerde etkin ve demokratik yönetsel yapıların oluşturulması için reform niteliğinde düzenlemeler yapılmıştır. Yerel inisiyatifin özellikle sivil toplumun güçlendirilmesi adına iyi yönetişim ilkelerinin hâkim kılınmasını öngören bu değişim sürecinin siyasi ve yönetimsel boyutunu bir grup araştırmacı 'politik bir değişim çă̆ ' olarak adlandırmıştır. Nitekim demokratik ve etkin yönetim alanındaki reformların öncüsü sayılan küreselleşme hareketi, genel olarak ulusal ekonomik politikaları, sermaye dolaşımını ve dış ticareti daha uluslararası perspektifte ele alan bir olgu olarak değerlendirilmektedir (Rhodes vd., 1997: 1-5). Nitekim bu alanda başarılı araştırmalarıyla bilinen bazı araştırmacılara göre "AB'nin ekonomik birlikten siyasal birliğe giderken gerekli adımları atabilmesinde yerelliğe verdiği önemin büyük katkısı olmuştur." (Tekeli ve İlkin, 2003: 69). Görüldüğ̈ gibi yerel, ulusal veya bölgesel düzeyde etkin işbirliği platformların oluşturulabilmesi için öncelikle sivil inisiyatifin güçlendirilmesi ve bu alandaki örgütlenmelerin desteklenmesiyle mümkündür. Bu minval üzere KEI'nin yazımızda ifade edilen beklentiler doğrultusunda daha etkin olabilmesi için yeni bir yönetsel felsefeyle köklü bir yapılanmaya ve yeni bir eylem stratejisine ihtiyacı gözükmektedir. $\mathrm{Bu}$ yöndeki tespit ve önerilerimiz aşağıda maddeler halinde sunulmuştur:

1. Öncelikle bölge ülke vatandaşlarının ve bunların adına hareket eden sivil toplum kuruluşlarının yakın diyalog ve işbirliği içinde bulunabilecekleri platformların geliştirilmesi önemlidir. Örneğin bölge ülkelerin sivil toplum kuruluşlarının ortak hareket etmelerini teşvik edici çeşitli proje yarışmaları organize edilebilir. Burada amaç toplumların birbirlerini tanımaları ve birlikte çalışarak bir şeyleri başarabileceklerini görmeleri sağlamak olmalıdır. Bu doğrultuda, belirli bir deneyimden sonra bölge ülkelerini kapsayan çatı sivil toplum kuruluşları oluşturulabilir. Yeterli kapasite oluşumundan sonra bu tür çatı örgütlerin bölge ülkelerinin demokratikleşmesi, daha iyi yaşam kalitesi, barış ve huzurun sağlanması gibi konularda hayati derece rol üstlenebilecekleri görülecektir. Hatta bölge ülkelerinin politikacılarına ilham kaynağı olacak çeşitli stratejileri oluşturabileceklerdir.

2. Bölge ülke üniversiteleri arasında işbirliğinin geliştirilmesi, araştırmacı ve öğrenci değişimi gibi konuların ele alınması ilişkilerin geliştirilmesi adına önem taşımaktadır. Üniversitelerin ortak projeler üzerinde çalışmaları ile diğer kamu kurumları ve sivil toplum kuruluşlarının da katılabileceği geniş işbirliği platformları oluşturulabilmektedir. Üniversiteler bu gibi alanlarda sürdürülebilir işbirliğinin oluşturulması ve geliştirilmesinde etkin rol oynayabilmektedirler. Faaliyetlerini akademik kariyerlerinin parçası veya devamı olarak gören araştırmacıların içinde oldukları projelerin sürdürülebilirliği (sustainability) ve yaygın etkisi (wider impact) daha etkin olabilmektedir.

3. Bölge ülkeleri arasında işbirliğinin geliştirilmesine yönelik yeni stratejilerin geliştirilmesi amacıyla proje yarışmaları düzenlenerek finanse edilebilir. Bu tür yarışmalara sivil toplum kuruluşları, üniversiteler ve hatta kamu kurumları katılabilir. Böylelikle bölgenin huzuru ve refahı için birlikte çalışmanın ve diyalog yollarının geliştirilmesi yönünde farkındalık ve bilinç artırılabilir. 
4. Sektörlerine göre iş dünyasının temsilcilerin bir araya gelmeleri sağlanarak bölge ülkeleri arasında ticari işbirliğinin geliştirilmesi büyük önem taşımaktadır. Bu amaç doğrultusunda 1993 y1lında kurulan Karadeniz Ekonomik Işsbirliği $\dot{I}_{s ̧}$ Konseyi'nin yetersiz kaldığı veya beklenileni sağlayamadığı ortadadır. Sektörlere göre proje desteklerinin verilmesi, ortak kuluçka merkezleri ve AR-GE merkezlerinin finanse edilmesinin teşvik edilmesi yeni işbirliklerini hızlandırabilir. Ayrıca özel sektörün, araştırma merkezlerinin ve üniversitelerin buluşarak disiplinler arası yeni işbirliği firsatlarını konuşabilecekleri sempozyum ve fuarları organize edilebilir.

\section{Etik Standart ile Uyumluluk}

Çıkar Çatışması: Yazarlar herhangi bir çıkar çatışmasının olmadığını beyan eder.

Etik Kurul İzni: Bu çalışma için etik kurul iznine gerek yoktur. 


\section{KAYNAKÇA:}

Göymen, K. 2004. "Yerel Kalkınma Önderi ve Paydaşı Olarak Belediye". Yerel Kalkınmada Belediyelerin Rolü Uluslararası Sempozyumu, Pendik Belediyesi Kültür Yayınları (Yayın no: 21), 49-81.

Demirkaya, Y. 2006. "Küreselleşmenin Kamu Yönetimi Üzerine Etkisi: Türkiye Örneği”. Marmara Üniversitesi, Avrupa Birliği Enstitüsü, Avrupa Araştırma Dergisi, vol. (14/2), 133-150.

Rhodes, M., Heywood, P., Wright, V., (Eds.). 1997. Developments in West European Politics, London: Macmillan.

Tekeli, İ., İlkin, S. 2003. Avrupa Birliği, Türkiye ve Yerellik, İstanbul: IULA- EMME.

Erkan, B., ve Batbaylı, Ş., 2017. "Karadeniz Ekonomik İşbirliği Örgütü (KEİ) Üyesi Ülkelerin Küresel Pazarlardaki Karşılaştırmalı Üstünlükleri,” Marmara Üniversitesi Siyasal Bilimler Dergisi, Cilt 5, Özel Sayı, Nisan 2017, ISSN 2147-6934, ss. 31-49

Yalçınkaya, A., 2017. "Kuruluşundan Günümüze Karadeniz Ekonomik İşbirliği Örgütü,” Marmara Üniversitesi Siyasal Bilimler Dergisi, Cilt 5, Özel Sayı, Nisan 2017, ISSN 2147-6934, ss. 116

Karadeniz Ekonomik İşbirliği Örgütü (KEİ), http://www.mfa.gov.tr/karadeniz-ekonomik-isbirligiorgutu-_kei_tr.mfa Erişim Tarihi: 09.05.2019

Oktay, E. G., 2006. "Türkiye'nin Avrasya'daki Çok Taraflı Girişimlerine Bir Örnek: Karadeniz Ekonomik İşbirliği Örgütü,” Uluslararası İlişkiler, Cilt 3, Sayı 10, 2006, ss. 149-179

Kiraz, S., 2018. “Türk Dış Politikasında Çok Yönlülük Denemeleri Bağlamında Karadeniz İşbirliği Örgütü ve D-8'in Karşilaştirmalı Olarak Analizi,” Turkish Studies, Volume 13/14.

Tsardanidis, C., 2005. "The BSEC: From New Regionalism to Inter-regionalism," Agora Without Frontiers, Volume 10-4, pp. 362-391. 